\title{
Stone Fish and Stingrays - Some Notes on the Injuries That They Cause to Man
}

\author{
Maj N K Cooper \\ FRCS(Ed),RAMC \\ Trainee in Occupational Medicine
}

AMD5a, Room 509, First Avenue House, High Holborn, London WCIV 6HE

SUMMARY: A review is presented of past and present records of injuries caused by these fish with particular reference to the occasional fatalities that have ensued.

The wide geographical range of species of both types indicate a variety of current Service postings where such injuries can be sustained.

The pharmacological actions of the venoms of both types are summarised as far as they are known.

Modern lines of management are described which stress the need for thorough debridement of these injuries.

\section{Introduction}

After preparing a historical vignette of the death during the First World War following envenomation by a stone fish, of an Australian Army Medical Corps officer on Thursday Island in the Torres Strait(1), it was suggested to this author that a review of the effects on man of stone fish and stingray injury would be of interest to readers of the Journal. A 17 month period spent as an intern and resident medical officer at Cairns Base Hospital, in far north Queensland, necessarily meant my undertaking the out-patient and sometimes the inpatient care of victims of these fish. The best description that I came across, whilst there of the effects of stone fish venom on man was in the pages of a paperback reprint of a minor Edwardian classic. It read as follows:

"Suppose that fella nail go along your foot, you sing out all a same bullocky all night. Leg belonga you swell up and jump about? Bingie (belly) belonga you sore fella. Might you die."(2)

E J Banfield, an English journalist who sought relief from overwork in a hedonistic existence on one of the beaches of Dunk Island off the North Queensland coast of Australia, published the above verbatim description by a local Aboriginal of the effects of a stone fish sting in his Confessions of a Beachcomber in 1908. No casualty officer faced with a recently envenomated patient would find much in this description to argue with.

However all medical practitioners who manage cases of stone fish and stingray envenomations will sooner or later encounter the lurid folk image which these fish project in the minds of the public. All too often this image is at best inaccurate and at worst positively dangerous. That one's fellow practitioners can also share similar beliefs has been a surprisingly frequent as well as a disconcerting experience to the author.

This paper aims to dispel such misconceptions by presenting a review of past and current literature, with particular reference to generally accepted modes of treatment of the injuries which these fish can cause to man. As the geographical range of stringray and stone fish species extends through the tropical Atlantic, Indian and Pacific Oceans, with specimens of both types being recorded from sites up to $15^{\circ}$ of latitude north and south of the tropics(3), it may be seen that there are a wide $>$ variety of current Service postings where such injuriesc can present.

For the purposes of this review stone fish are defined 0 as species of the Synanceia genus and stingrays 25 members of the Rajiformes order (skates and rays).

\section{Stone Fish and Stingrays Contrasted}

The Post-Graduate Bulletin of the Medical Committee of the University of Sydney for Maren 1963(4) describes the structure and function of the venom glands of the stone fish thus:-

"Along the back of the stone fish is a row of thirteen stro旁 spines, hidden by puckered skin which also conceals the bags of poison, one on each side of each of these spines. Though the skin of the fish may be easily slipped back to leave the end of a dorsal spine protruding, the poison glands are more firmly secured, and their position is such that their venom is squeezed out by the slightest pressure. It is then forced along deep grooves which extend up each? side of the spine to their tips, and is so conveyed into the depths of any wound they may inflict (Fig 1). The spines of a stone fish can penetrate a sandshoe to enter a wader's foot.

The poison is extremely virulent, the stone fish being the most venomous fish known, and immediately causes such fearful pain that a victim may become almost. demented, and may fall in the water and risk drowning. His limbs may swell, and if he cannot obtain medical treatment, he may die."

The Post-Graduate Bulletin continues:-

"In the South Sea Islands the stonefish is called Nofu, No'u or Nohu (the "waiting one"), and is dreaded by the natives, who treat wounds from it by applying leaves too the unaffected parts!

The Australian Aborigines of the Cape Bedford district, Queensland, used to produce a beeswax model $l_{\sigma}^{\omega}$ 
of the "Dornon", as they called the stonefish, for part of their initiation ceremonies. The model was placed on the ground and the poisonous nature of the fish was explained to the youngsters by the elder men, who danced around and around and pretended to search for and spear it. Finally, one native trod on the sticks which served as spines on the model and, acting as if he was poisoned, uttered an unearthly yell and fell to the ground as if in agony. Notwithstanding such dramatic demonstrations, some of the keenest-eyed natives occasionally suffer through failing to recognize this hidden danger of the reefs.

The flesh is edible, indeed delicious, so natives are only too eager to turn the tables on the fish by spearing it before it can wound them."

By contrast, the same publication describes the stingray as a very flat shark type and continues:-

"If you can imagine that the shark's five gill slits have come to lie on the lower surface of the body instead of the sides of the head and body, and the whole thing has been squashed as though it had gone through a mangle, then you get the ray, which is dark on the top and light below. The dangerous kind that we have to look for is the stingray, in which there is a long barbed spike on the back. It has very fine venom glands and ducts."

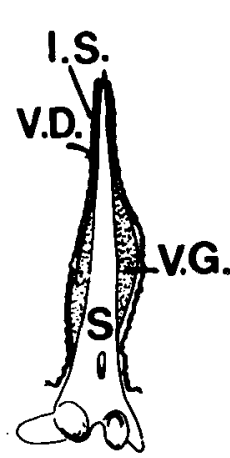

A.

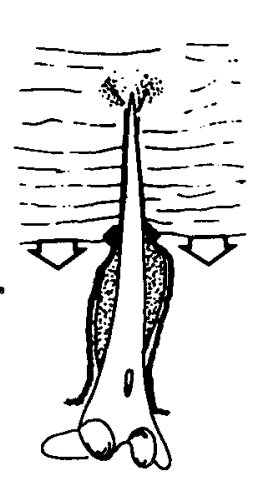

B.

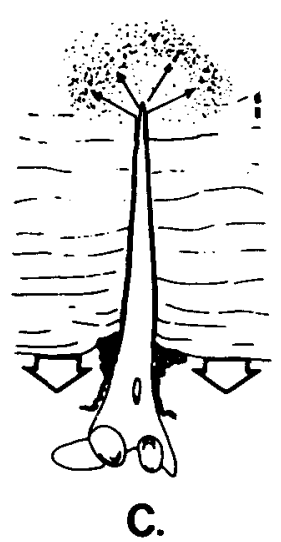

Fig 1. Venom apparatus of a stone fish:

A. Dorsal spine viewed from behind, showing paired lateral venom glands (VG). Note tip of spine (S) and narrow venom ducts (VD), both passing through a narrow opening in the tough integumentary sheath (IS).

B. \& C. A human has trodden upon the fish, the skin is pushed down the spine (large arrows) and the venom gland is compressed by the crumpled sheath. This pressure forces the venom gland to empty up the narrow duct, and venom and glandular tissue spurt (small arrows) into the deep tissue of the foot.

Reproduced from Sutherland K. "Australian Animal Toxins: the creatures, their toxins and care of the poisoned patient." Oxford University Press. Melbourne. 1983.
This author's personal observations which were in warm tropic seas off Queensland and Oman, werilst others were doing his medical work onshore, were stonefish are almost always sedentary in habit andewill move only when disturbed, and then clumsily and with a considerable degree of reluctance. A stingray orpthe other hand is a fast swimmer which will thereby adqthe momentum of its body (which may weigh ten of pounds) to the force of the musculature behin $\$$ its barbed spike.

Considerable mechanical damage can thereb $\frac{\bar{\rho}}{5}$ be caused to the unwary human who swims over a large stingray in shallow water, or who accidentally stepos on one. The defensive, reflex action of a stingray to stich contact is usually a sudden thrust of its tail forward-and downwards, driving the spike into the victim (Fig 2)

The violent actions of a stingray spike in human fesh $_{\text {. }}$ lead to tissue necrosis which summates with the necpotic action of the injected venom, as well as with the efects of bacterial contamination and retained integurment from the spike. The end-result of delayed treatment phay therefore be extensive tissue loss necessitating \&kin grafting(1).

It can be appreciated therefore, that in both stonghish and stingray injuries a considerable degree ${ }^{3}$ of contamination is present. Sutherland(5), Jwhose knowledge of the subject is encyclopaedic, sumranses the situation thus:- "The wounds are poteresilly contaminated with bacteria, but may contag $\Phi$ (in addition) a trail of glandular and integumentary shegath material as well as necrotic tissue."

Pharmacology of Stone Fish and Stingray Venom

Laboratory work on stingray and stone fish has not been comprehensive, although a stonefish antivenom has been developed by Commonwa galth Serum Laboratories in Australia(5). All fish verioms have been shown to be thermolabile at mammalian $\overrightarrow{\text { grody }}$ temperatures, a fact which many authorities Bave regarded as proof of the efficacy of a time-hono $\bar{q}$ red mode of treatment of fish envenomations, - viz. immersing the affected part in water as hot as the vietim can bear.

Stingray (Urolophus species) venom has been s通wn to contain a toxic protein with a molecular weight of approximately $100,000(5)$. In monitored cats a bradycardia with S-T wave alterations suggestive of ischaemia occurred when Urolophus venom Jwas administered intravenously, but neuromus transmission was not disturbed. Cats receiving a leghal dose of Urolophus venom showed pupillary dilatafion, ataxia, salivation, incontinence and collapse. The intravenous lethal dose (LD) of the lyophilised veftom was found to be $28 \mathrm{mg} / \mathrm{kg}$ in mice.(5)

Wiener(6) dissected out stone fish venom glands forom live specimens of Synanceja trachynis averaging 700 grams in weight and found an average of $6 \mathrm{mg}$ verom per spine. Venom yields per fish ranged from 49 ffr 88 

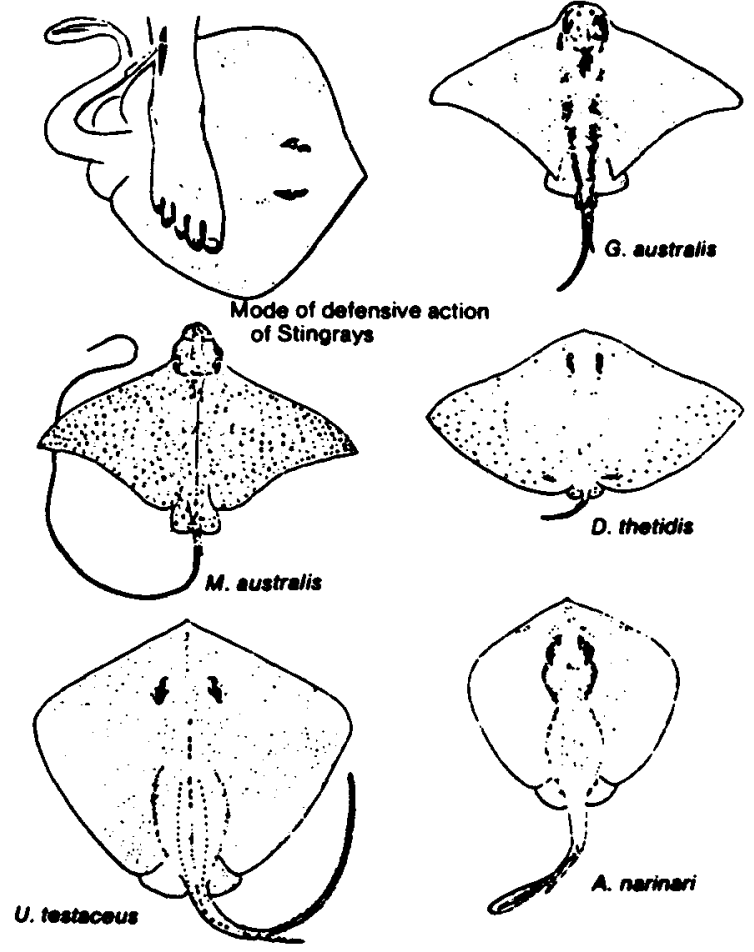

Fig 2. The mechanism of the Stingray wound and some common Stingrays.

Reproduced from Sutherland K. "Australian Animal Toxins: the creatures, their toxins and care of the poisoned patient." Oxford University Press. Melbourne. 1983.

mg. Regeneration of venom glands and venom is estimated to take three weeks after the gland has discharged(7). Wiener(6) found the LD to be $0.007 \mathrm{mg}$ intravenously and $0.05 \mathrm{mg}$ subcutaneously in mice weighing 15 grams each.

The same researcher(6) went on to show that an injection of $0.17 \mathrm{mg} / \mathrm{kg}$ of stone fish venom into an anaesthetized and monitored dog gave transcient hypertension and apnoea. Higher doses produced cardiac and respiratory arrest within two minutes. Electrocardiographic changes such as atrio-ventricular block and ventricular fibrillation occurred in monitored rabbits given intravenous stone fish venom(7). Other workers $(8)$ showed hypotension, respiratory distress and muscular paralysis, suggesting a myotoxic property of stone fish venom. The major toxin is a labile protein with a molecular weight of approximately 150,000 , and the venom contains a potent hyaluronidase and a capillary permeability factor(9). No effect was shown by the venom on blood clotting nor did it cause haemolysis.

A survey of reports of Commonwealth Serum Laboratories stone fish antivenom(5) revealed that of 267 reports collected over the period 1965-1981, 129 originated in Queensland, 35 in the Northern Territory, 54 in Western Australia and 49 overseas. Eighty-three 3 percent of the cases were males and apart from three $\stackrel{\mathbb{Q}}{\Omega}$ persons injured on their arms or their wrists, all stings $\bigcirc$ occurred either on the hands $(36 \%)$ or feet $(63 \%)$. This 응 pattern of distribution between hands and feet suggests that many of these stings could have been avoided. The $\overrightarrow{\vec{F}}$ average age of victims was 27 years with four children $\stackrel{\oplus}{\rightarrow}$ under the age of 5 years receiving antevenom for the stings. No deaths were reported.

\section{Common Misconceptions}

In spite of the larger amount of material on stonefish envenomation which has already been published in print and on film, it is still possible in 1990 for medically $\overrightarrow{\vec{\omega}}$ qualified authors to publish a letter in the British $\stackrel{5}{ }$ Medical Journal entitled: "Stone fish bite"(10) dealing with a case of human envenomation which they had managed. The title words "fish bite" $(10)$ inevitably conjure up the image of an injury similar to the bite of a venomous snake rather than the true picture of $\dot{\omega}$ penetration by the poisonous dorsal spines of the fish.

Sutherland(11) responded to this misconception with a helpful update on the management of these injuries. $\mathrm{He}$ includes the interesting fact, that although $\overrightarrow{0}$ immersion of the affected part in warm but not scaldirir water may indeed provide appreciable relief, there apparently no evidence that this manoeuvre in faet $\stackrel{\Phi}{-}$ denatures the venom and pain may return immediate when the heat ceases to be applied.

\section{Treatment}

In the same letter, Sutherland(11) goes on to emphasize the importance of local, and if necessary, regional anaesthesia in the management of pain $\mathbb{\perp}$ produced by stone fish venom. His recommendation of $\overrightarrow{\vec{A}}$ systemic opiates is disputed, at least for initial pain $\frac{0}{3}$ management by an Australian consultant in intensive care who has extensive experience in managing this problem(12).

There is no doubt of the effectiveness of stone fish antivenom in reducing the pain as well as the other local and systemic effects of stone fish envenomation. The antivenom is supplied by Commonwealth Serum $\mathbb{\mathbb { D }}$ Laboratories, Melbourne, as a pure equine $\mathrm{F}(\mathrm{ab}) 2 \stackrel{\mathrm{F}}{\mathrm{F}}$ preparation(5). Ampoules contain approximately $2 \mathrm{ml}$ 훅 which will in vitro neutralize $20 \mathrm{mg}$ of stone fish venom. The antivenom is recommended in all cases except $\delta$ where pain is only moderate, or else where the case has $₹$ reached medical care (and antivenom) some time after 을 the sting and is clinically improving.

The initial dose of the antivenom depends upon the number of spines which have punctured the skin thus:

1-2 punctures, 2,000 units (one ampoule)

3-4 punctures, 4,000 units (two ampoules)

5-6 punctures, 6,000 units (three ampoules) 
The normal precautions for administering any antivenom are to be observed. Stone fish antivenom is usually given intramuscularly except in severe cases where the pain is widespread or the patient shocked when the intravenous route should be considered. Injection of antivenom around the stung area may worsen the local effects of venom already there, and should never therefore be attempted(5).

In his recent letter to the British Medical Journal(11) Sutherland also points out the deleterious effect of using a tourniquet after a stone fish sting which merely increases discomfort and worsens the local necrosis caused by the venom. Pressure immobilisation of the affected part (the universally recommended practice for snake bite) is also not advised for stone fish envenomation, as it is considered best for the concentrated necrotizing venom to be allowed to diffuse freely away from the region.

Sutherland continues(11):-

"Infection often occurs with this type of injury. It should be remembered that marine bacteria comprise a wide range of organisms, and many are resistant to common antibiotics and also may require saline media for culture. It follows that debridement should be assisted by washing the wound well with fresh or preferably sterile water. The drug of first choice is trimethoprim-sulphamethazole. Tetanus prophylaxis should also receive attention."

The management of stingray spike injuries should follow the same lines as for stone fish envenomation, although it has not been considered necessary to develop a stingray antivenom(5). The dagger-like action of the spike of a large stingray can, as mentioned earlier, cause extensive mechanical damage to the point of serious and sometimes fatal injury.

\section{Serious Injuries and Deaths from Stingrays}

Cleland(13) reported a case of penetration of a fisherman's leg between tibia and fibula in 1942 where the creature which measured some $3 \mathrm{~m}$ in width had become entangled in a fishing net. The victim was left with wounds $17 \mathrm{~cm}$ on the outer side and $10 \mathrm{~cm}$ on the inner side which healed slowly by second intention. Cadzow(14) reported in 1960 an abdominal injury in a 7 year old native child who captured a stingray in shallow water. Two spines broke off flush with the skin, and were found at operation to have penetrated the right lobe of the child's liver. Apart from a superficial wound infection the patient made an uneventful recovery. A more recent case reported by Cross in 1976(15) was of a 16 year old Polynesian schoolboy whose bowel was perforated in four places by the stingray spike. After surgical repair he made a good recovery.

Fatalities following human encounters with stingrays have included a stab wound to the pericardium and left ventricle in a previously fit adult woman who swam over a large stingray in shallow water off a beach in New Zealand in 1938(4). A fin of the fish responsible was seen by a watcher on the beach who then pulled the ding victim from the water.

Another case involved an Australian Army Serg䀜的 who died in 1945 of a stab wound to the left fifth intercostal space $1.25 \mathrm{~cm}$ wide and $7.6 \mathrm{~cm}$ deep which was shown at autopsy to have perforated the left plecaral cavity, the pericardium and the left ventricle(4). Fere the fatal injury was inflicted in the opaque waters of an open air salt water swimming bath which communicated with the sea. Although the stingray was never actuglly seen, an exhaustive search revealed no objects in the swimming bath which could have impaled the vicim. The coroner's finding was:- "death by haemorrhage (sic) after being struck by a stingray."

Such freak fatalities from encounters with stingrays remained for many years the only cases recorded in $\overrightarrow{\text { th he }}$ medical literature. In 1989 however two further fatalisies were documented. In the first a previously health 12 year-old boy died in Queensland six days after sustaining a penetrating chest injury from a stingray spike. Degth was a result of cardiac tamponade secondary to venominduced, localized myocardial necrosis and spontaneous perforation after direct penetration of the right ventiple with injection of venom(16).

The second recent fatality following injury $b_{y}$ a stingray occurred on Waya Island, Fiji in Novömber 1989(17). Here death occurred some hours afterghe victim was stabbed in the thigh by a large stingrayow bilst scuba diving. The stingray spike divided the fegrmoral artery and death supervened from uncontrollable $560 d$ loss, Waya Island being remote from surgical coge In this context older readers of this Journal may recalthe name of Pinkley Neofitou aka Newly, a well-ino NAAFI manager in the Suez Canal Zone before 195 , and elsewhere thereafter. Sadly, the latter victim waohis elder son who, until the accident had been runninof an extremely successful diving resort thereby followinghis family tradition of catering for the recreational need of others.

\section{Conclusion}

This short survey of the damage which two type tropical fish can inflict on humans indicates that problem should be viewed from two perspectives. Fis tly the cause of death or injury given by attendants on victim, or even on a tombstone is not necessẫily correct(1). Secondly the occasional cases of serious injury or death following encounters with these creatures should be viewed against a statisticallyof larger group of fatal and non-fatal accidents. This greup comprises accidents which occur due to road troffic whilst travelling to the coast, or else are caused through drowning whilst bathing or diving or being involvedon a boating accident.

Nevertheless dive-leaders and doctors to Seroice diving expeditions should be aware of the smallnbut significant danger which both stone fish and stingirays pose in tropical and subtropical waters, and of the gist- 
aid measures needed to counter the biochemical and mechanical effects which these fish can cause in man.

The old adage of prevention being better than cure is nowhere more apt than in encounters with poisonous creatures of any type. Recognition and avoidance will prevent virtually all encounters with these fish from being anything more than the basis of a good story when the diver returns to shore.

\section{Acknowledgement}

I thank the Department of Medical Illustration, Royal Army Medical College, Millbank for preparing Figures 1 and 2 .

\section{REFERENCES}

1. COOPER N K. Historical Vignette - The death of an Australian Army Doctor on Thursday Island in 1915 after envenomination by a stone fish. $J R A r m y$ Med Corps 1991; 137: 104-105.

2. BANField E J. Confessions of a Beachcomber. London 1908 reprinted 1977.

3. Carcasson R H. A Field Guide to Reef Fishes. London: Collins, 1977.

4. Whitley G P. Dangerous Australian fish: in The Post Graduate Bulletin of the Medical Committee of the University of Sydney, March 1963:48.

5. Sutherland S K. Australian Animal Toxins: the creatures, their toxins and care of the poisoned patient. Melbourne: Oxford University Press, 1983; 440.
6. Wiener S. Stone fish venom. The Post Graduate Bulletin

7. SAUNDERS P R. Venom of the stone fish Synanceja市 verrucosa. Science 1959; 129: 272-4.

8. Austin L, Cairncross K D, McCallum I A N. Someo pharmacological actions of the venom of the stone fisho Synanceja horrida. Arch int Pharmacodyn Ther 1961; 131:

9. Austin L, GILlis R G, YouatT G. Stone fish venom: some biochemical and chemical observations. Aust J Exp Biol Med Sci 1965; 43: 79-90.

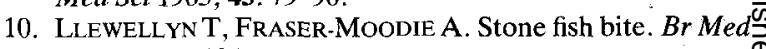
$J$ 1990; 300: 134.

11. SutherLAND S K. Stone fish bite. Br Med J 1990; 300: 679.

12. AcotT C J. Stone fish envenomation. Undersea Biomed Res (Suppl to Vol 17) 1990; 242: 146.

13. Cleland J B. Injuries and diseases of Man in Australia attributable to animals except insects, series V: Mammals, $\omega$ Fish, Spiders, Mites and Ticks etc, Shell fish, Sponges, Protozoa, Med J Aust 1942; 2: 339-45.

14. CADzow W H. Puncture wounds of the liver by stingray spines. Med J Aust 1960; 1: 936-7.

15. Cross T B. An unusual stingray injury - the skindiver at risk. Med J Aust 1976; 2: 947-8.

16. Fenner P J, Williamson J A, Skinner R A. Fatal and non-fatal stingray envenomation. Med J Aust 1989; 151:0 $621-625$.

17. KNIGHT J. Obituary: Andonis Neofitou, better known Anthony Newly. SPUMS J 1989; 19(4): 197. 